\title{
Introduction
}

\section{Giving it your best shot}

Jason P. Sheehan, M.D., Ph.D.

Department of Neurological Surgery, University of Virginia Health System, Charlottesville, Virginia

In May 2014, the Leksell Gamma Knife Society held its 17th meeting in New York City (Fig. 1). The theme of the meeting was "Giving It Your Best Shot." The theme resonates well with those practicing in the field of Gamma Knife radiosurgery. In fact, neurosurgeons and radiation oncologists performing Gamma Knife radiosurgery are frequently faced with challenging situations, and they must perform as well as possible despite uncertainty and occasionally long odds for success. The Gamma Knife has stood the test of time for more than 4 decades. For hundreds of thousands of patients, the Gamma Knife has delivered success far more often than failure.

New York is one of the most vibrant and diverse cities in the world. The breadth of the scientific proceedings, liveliness of the discourse, and the diversity of participants hailing from more than 40 countries mirrored the ethos of the host city. Scientific proceedings covered such topics as neuro-immunology, fractionation, ethics, and epilepsy. In a sign that an old approach can become new again, Gamma Knife-effectuated ablation and behavioral radiosurgery were also topics covered in the plenary session. Fractionation not just with the Gamma Knife Extend but also with the Perfexion Plus will bring further innovation to the field. Multisession Gamma Knife radiosurgery is also likely to prove paradigm shifting.

In a forward-thinking fashion, the meeting covered the topic of creating a Gamma Knife registry. Such a registry could allow for far-reaching, multicenter scientific studies. It could also help to advance the field in a more rapid fashion than any single individual center could do by itself. After all, the scientific literature related to Gamma Knife radiosurgery is mature and comprehensive. The remaining questions are more difficult to answer,

Please include this information when citing this paper: DOI: 10.3171/2014.6.GKS141282.

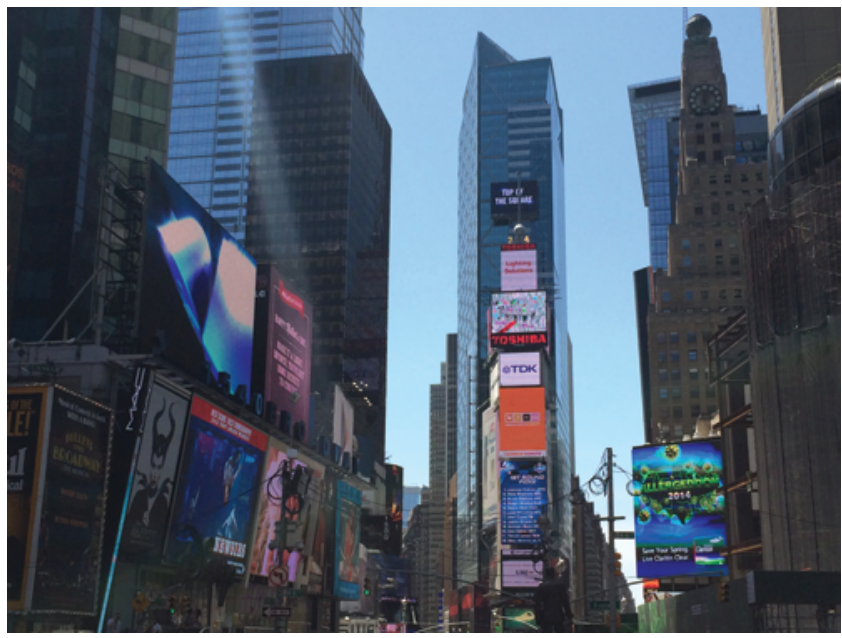

FIG. 1. Times Square in New York City. Photograph by Jason P. Sheehan.

and such questions frequently require greater amounts of high-quality data to answer. A Gamma Knife registry should provide the platform for acquiring and analyzing requisite data. Also, the registry could help to identify areas for practice improvement as a clinician compares his/ her results to peers. Finally, the registry may demonstrate areas for improved efficiency, quality, safety, and costeffectiveness in Gamma Knife radiosurgery.

The articles contained in this supplement represent some of the more notable scientific work at the meeting. I would like to thank the following reviewers for their assistance: Drs. Veronica Chiang, Arnold Etame, Hideyuki Kano, Anthony Kaufmann, Jonathan Knisely, Douglas Kondziolka, James Larner, Cheng-Chia Lee, L. Dade Lunsford, Ajay Niranjan, Gail Rosseau, Arjun Sahgal, David Schlesinger, John Suh, Zhiyuan Xu, and Chun-Po Yen. The Gamma Knife meeting in New York proved successful by any metric. The Gamma Knife remains an important neurosurgical tool, and the field appears as alive as the city of New York itself.

(http://thejns.org/doi/abs/10.3171/2014.6.GKS141282)

\section{Disclosure}

The author reports no conflict of interest. 